\title{
Association Between Mean Arterial Pressure and Survival in Patients Admitted to the Intensive Care Unit After Cardiac Arrest With Vasopressor Support: A Retrospective Study
}

\section{Zhimin Li}

Department of Critical Care Medicine,Beijing Tiantan Hospital,Capital Medical University,Beijing,China Dawei Zhou

Department of Critical Care Medicine,Beijing Tiantan Hospital,Capital Medical University,Beijing,China Shaolan Zhang

Department of Critical Care Medicine,Beijing Tiantan Hospital,Capital Medical University,Beijing,China Lei Wu

Department of Critical Care Medicine,Beijing Tiantan Hospital,Capital Medical University,Beijing,China Guangzhi Shi ( $\nabla 15866601260 @ 163 . c o m$ )

Department of Critical Care Medicine,Beijing Tiantan Hospital,Capital Medical University,Beijing,China

\section{Research article}

Keywords: Cardiac arrest, Mean arterial pressure, Vasopressor support, Prognosis

Posted Date: July 14th, 2020

DOI: https://doi.org/10.21203/rs.3.rs-41166/v1

License: (c) (i) This work is licensed under a Creative Commons Attribution 4.0 International License. Read Full License 


\title{
Association between mean arterial pressure and survival in patients admitted to the
} intensive care unit after cardiac arrest with vasopressor support: a retrospective study

\author{
Zhimin $\mathrm{Li}^{1}$, Dawei Zhou ${ }^{1}$, Shaolan Zhang ${ }^{1}$, Lei Wu ${ }^{1}$, Guangzhi Shi ${ }^{1 *}$ \\ Zhimin Li and Dawei Zhou contributed equally to this work.
}

Authors:

Author 1: Zhimin Li, Academic degree: M.D.;

Institution: Department of Critical Care Medicine, Beijing Tiantan Hospital, Capital Medical

University, Beijing, China;

Major in: Critical care Medicine;

Email: tt15510296528@,163.com

Author 2: Dawei Zhou, Academic degree: M.D.;

Institution: Department of Critical Care Medicine, Beijing Tiantan Hospital, Capital Medical

University, Beijing, China;

Major in: Critical care Medicine;

Email: 112018000283@ccmu.edu.cn

Author 3: Shaolan Zhang, Academic degree: M.D.;

Institution: Department of Critical Care Medicine, Beijing Tiantan Hospital, Capital Medical

University, Beijing, China;

Major in: Critical care Medicine;

Email: shaolan_zhang@139.com

Author 4: Lei Wu, Academic degree: M.D.; 


\author{
University, Beijing, China;
}

Major in: Critical care Medicine;

Email: 1ei_wu@139.com

Corresponding author: Guangzhi Shi, Academic degree: M.D.;

Institution: Department of Critical Care Medicine, Beijing Tiantan Hospital, Capital Medical

University, Beijing, China;

Email: 15866601260@163.com 


\begin{abstract}
Background

Mortality among patients admitted to the intensive care unit (ICU) after cardiac arrest (CA) is high. Hemodynamic management in the phase of post-resuscitation is recommended by international guidelines, but the optimal mean arterial pressure (MAP) range is still unclear. The main objective of this study is to investigate the association between time spent in different MAP and ICU mortality in PCA patients admitted to ICU with vasopressor support.
\end{abstract}

\title{
Methods
}

It was a retrospective, observational study in cardiac arrest patients admitted to the ICU with vasopressor support during the first 24 hours. The main exposure was time spent in MAP. The primary outcome was ICU mortality. Associations between time spent in MAP and ICU mortality were evaluated using ten MAP thresholds: $100,95,90,85,80,75,70,65,60$, and $55 \mathrm{mmHg}$. Multivariable logistic regression analyses were used to test the association between time spent in different MAP categories and ICU mortality.

\section{Results}

The study included 1018 eligible subjects in ICUs from 156 hospitals, of which 453 (44\%) patients died during hospitalization and 208 (37\%) patients discharged home. A significant association was found between time spent in MAP and the ICU mortality when MAP thresholds of $\leq 55 \mathrm{mmHg}(\mathrm{OR} 1.25,95 \% \mathrm{CI}$ 1.09-1. 45, $\mathrm{p}=0.002)$ and $\leq 60 \mathrm{mmHg}(\mathrm{OR} 1.13,95 \%$ CI 1.02-1.24, $\mathrm{p}=0.014)$ were used. Thresholds of MAP $\geq 65 \mathrm{mmHg}$ were not associated with mortality. The percentage of time spent in MAP of $\leq 90 \mathrm{mmHg}$ (OR 1.09, 95\% CI 1.01-1.18), $\leq 95 \mathrm{mmHg}($ OR 1.12, 95\% CI 1.01-1.24,) and $\leq 100 \mathrm{mmHg}(\mathrm{OR} 1.19,95 \%$ CI 1.04-1.38) were associated with a higher odds ratio for discharged home outcome, suggesting that MAP 
of $\geq 90 \mathrm{mmHg}, \geq 95 \mathrm{mmHg}$ and $\geq 100 \mathrm{mmHg}$ were associated with lower probability of discharged home.

\section{Conclusions}

These results imply that for post-cardiac arrest patients with vasopressor support, time spent in MAP of $\leq 60 \mathrm{mmHg}$ or less was associated with higher ICU mortality and MAP of $\geq 90 \mathrm{mmHg}$ or more was associated with a lower probability for discharged home.

Keywords: Cardiac arrest, Mean arterial pressure, Vasopressor support, Prognosis.

\section{Introduction}

Patients admitted to the intensive care unit (ICU) after cardiac arrest (CA) have a high risk for death, with estimated survival 30-50\%(1-4). Despite science based guidelines for cardiopulmonary resuscitation (CPR), a large number of patients who achieve a return of spontaneous circulation (ROSC) often develop poor neurologic outcomes $(5,6)$.

After ROSC, hemodynamic dysfunction is the major injury associated with in-hospital mortality(7). Due to the tendency to hemodynamic lability and brain sensitivity to ischemia, cerebrovascular autoregulation may become "right-shifted", thus higher MAP may be beneficial to maintain sufficient cerebral perfusion(8, 9). Current guidelines recognized that the evidence for targeted blood pressure is weak and it is not clear whether the use of vasopressor to achieve an ideal blood pressure is associated with optimal clinical outcomes(10).

To test the optimal MAP range in patients who achieved ROSC, we studied patients admitted to multicenter ICUs. The purpose of this study is to investigate the association between time spent in different MAP thresholds during the first $24 \mathrm{~h}$ of ICU admission and survival in post-CA patients with vasopressor support. 


\section{Methods}

\subsection{Setting}

We performed a study analysis based on the eICU database (eicu-crd.mit.edu), which is a multicenter intensive care unit (ICU) database with high granularity data for 200,859 admissions admitted between 2014 and 2015 to one of 335 units at 208 hospitals located across the United States. A stratified random sample of patients was used to select patients for inclusion in the public dataset. The database contains baseline characteristics of patients with cardiac arrest, hospital admission parameters, vital status, relevant treatment, and clinical outcome data. A detailed description of the eICU has been previously published(11).

The eICU database was exempt from institutional review board approval and certified as meeting safe harbor standards by Privacert Cambridge, MA Health Insurance Portability and Accountability Act Certification no.1031219-2. The author (certification number: 28795067) was granted access to the database for research purposes, after completing a National Institutes of Health web-based training course (Protecting Human Research Participants).

\subsection{Study population}

All patients in the eICU database were eligible to be included in our study. As for those who admitted to ICU for more than once, only the first ICU stay was taken into account. All adult patients diagnosed with cardiac arrest were selected. Exclusion criteria were: (1) ICU stay $<24$ hours, (2) Missing mortality data, (3) No use of vasopressors, (4) Number of MAP measurements $\leq 144$ during the first 24 hours.

\subsection{Clinical variables}




\begin{abstract}
We extracted the following data: demographics, comorbidities, ICU types, hospital characteristics, Acute Physiology and Chronic Health Evaluation (APACHE) IV score, life support interventions, locations at hospital discharge, and length of stay in hospital and ICU.
\end{abstract}

The early-stage may be the most important after ROSC for cardiac arrest patients(12). MAP during the first $24 \mathrm{~h}$ in ICU was extracted, which was interfaced from bedside vital signs monitors into eCareManager as 5-min averages and archived as 5-min median values into the 'vitalPeriodic' table. For each patient, we calculated the mean MAP, median MAP, maximum MAP, minimum MAP, and time-weighted average MAP (TWA-MAP). Based on MAP values, 10 thresholds were used for evaluating, which were MAP $\leq 55 \mathrm{mmHg}, 60 \mathrm{mmHg}, 65 \mathrm{mmHg}, 70 \mathrm{mmHg}, 75 \mathrm{mmHg}, 80 \mathrm{mmHg}, 85 \mathrm{mmHg}, 90 \mathrm{mmHg}, 95 \mathrm{mmHg}$ and100mmHg.

\title{
2.4. Definitions
}

2.4.1. Time-weighted average mean arterial pressure (TWA-MAP)

The time-weighted index in the $24 \mathrm{~h}$ post-ROSC was defined as follows. For each patient, the multiplicative product of the MAP and the duration of exposure to that MAP were obtained. The products were summed up and divided by the total duration of post-resuscitation observation time to obtain the TWA-MAP. The TWAMAP equation for was.

$$
\text { TWA-MAP }=\frac{\left(\text { MAP }_{a} \times \text { Time }_{a}\right)+\left(\text { MAP }_{b} \times \text { Time }_{b}\right)+\cdots+\left(M A P_{z} \times \text { Time }_{z}\right)}{\text { Time }_{a+} \text { Time }_{b}+\cdots+\text { Time }_{z}} .
$$

TWA-MAP is a weighted measure of MAP, and a lower value implies more exposure to hypotension(13).

2.4.2. The time spent in mean arterial pressure (MAP) threshold

The time for each patient spent in different MAP thresholds during the first $24 \mathrm{~h}$ was defined as the time in each different MAP threshold divided by total time (1440 min). Figure1 displayed MAP every 5 minutes for 
one patient during the first 24 hours (1440 min) after admitting to ICU. For the missing data of timestamped MAP, we used last observation carried forward method to replace. A similar method was used to calculate the duration of MAP in other studies (14). The value of the analysis lies in exploring which MAP threshold leads to the loss of the association between MAP and ICU mortality, as this threshold may represent the appropriate MAP target in post-CA patients.

\subsection{Outcomes}

The primary outcome measure was ICU mortality. Secondary outcomes were hospital mortality and the proportion of discharged home. The discharged home outcome was used for representing a good neurological outcome since the eICU database lacks evaluation of a neurological function at the time of discharging from the hospital.

\subsection{Statistical analysis}

The normality of the data was initially assessed. Continuous variables were reported using their means with the $95 \%$ confidence interval. Categorical variables were shown in the form of numbers and percentages. The chi-squared test or Fisher's exact test and Student's t-test or Kruskal-Wallis tests were used for group comparisons when appropriate.

Due to the results of dichotomy, we used multivariable Logistic regression models for analysis. Independent predictors for ICU mortality were shown as odds ratios (ORs). Crude and adjusted ORs of time spent in different MAP thresholds for outcomes were calculated. The multivariate logistic regression models were constructed with variables of a $P$-value $<0.20$ identified by the univariate analysis or considered clinically important. The percentage of time spent in ten MAP thresholds, as a continuous variable, were separately entered the multivariable model with confounders. The stepwise backward 
elimination method was used to remove variables with $P$-value $>0.1$. Potential multicollinearity was tested using the variance inflation factor and goodness of fit was tested for all logistic regression models.

All analysis was performed using R version 3.5.1(www.r-project.org). PostgreSQL (version 10, www. postgresql.org) was used for data extraction. A two-sided $P$ value of less than 0.05 was considered statistically significant.

\section{Results}

200,859 patients were recorded in the eICU database. After exclusion, 1018 subjects were analyzed (Fig.2). Among them, 453 patients died, giving hospital mortality 44.5\%. 208 (37\%) patients discharged home in survivors, with a median length of stay in hospital and ICU were respectively 6 days (IQR, 4-12) versus 4 days (IQR, 2-6.75). The main characteristics of the included subjects were reported in Table 1. Non-survivors had significantly greater severity of illness as represented by APACHE IV. No other differences were found between non-survivors and survivors.

Table 2 showed MAP and treatments during the first $24 \mathrm{~h}$ for all patients. There were no differences in using mechanical ventilation, dialysis, dopamine and dobutamine between survivors and non-survivors. The survivors had higher minimum MAP (51 vs $49 \mathrm{mmHg}, P=0.003$ ), and a higher proportion of using percutaneous coronary intervention $(\mathrm{PCI})(14 \%$ vs $8 \%, P=0.006)$. The non-survivors had a higher percentage of time spent in MAP of $\leq 55 \mathrm{mmHg}$ and $\leq 60 \mathrm{mmHg}$ categories, using hypothermia (38 vs $29, P$ $=0.004)$,vasopressin( $26 \%$ vs $17 \%, P<0.001)$, phenylephrine $(17 \%$ vs $11 \%, P=0.016)$, norepinephrine ( $88 \%$ vs $82 \%, P=0.004)$, and epinephrine (92 vs $84, P<0.001)$.

Fig.3 showed unadjusted ICU mortality of four time-categories (0-25\%, 25-50\%, 50-75\%, and 75$100 \%)$ spent in ten MAP thresholds $(55 \mathrm{mmHg}, 60 \mathrm{mmHg}, 65 \mathrm{mmHg}, 70 \mathrm{mmHg}, 75 \mathrm{mmHg}, 80 \mathrm{mmHg}$, 
$85 \mathrm{mmHg}, 90 \mathrm{mmHg}, 95 \mathrm{mmHg}$, and $100 \mathrm{mmHg}$ ). Of note, when the percentage of time spent in MAP below $60 \mathrm{mmHg}$ or $55 \mathrm{mmHg}$ was more than three quarters, the ICU mortality were as high as $80 \%$ and $82 \%$, respectively. Obviously, a high percentage of time spent in MAP of $\leq 55 \mathrm{mmHg}, \leq 60 \mathrm{mmHg}$ and $\leqslant$ $65 \mathrm{mmHg}$ had higher ICU mortality, while among other 8 quantiles had no obvious difference.

Table 3 displayed the results of multivariable logistic regression models. We calculated unadjusted and adjusted odds ratios for ICU mortality with different MAP thresholds. In the adjusted analysis, a high percentage of time spent in MAP of $\leq 55 \mathrm{mmHg}$ and $\leq 60 \mathrm{mmHg}$ was associated with higher hospital mortality, and the adjusted odds ratios are 1.25[1.09,1.45] and $1.13[1.02,1.24]$ respectively.

Supplemental Fig.1 displayed adjusted ORs for ICU mortality and discharged home outcomes for different MAP thresholds. A high percentage of time spent in MAP $\leq 55 \mathrm{mmHg}$ had higher hospital mortality (OR, 1.20[1.05,1.41]), but was not associated with discharging home. A high percentage of time spent in MAP of $\leq 90 \mathrm{mmHg}, \leq 95 \mathrm{mmHg}$ and $\leq 100 \mathrm{mmHg}$ had a higher proportion of discharging home, and the adjusted OR is $1.09[1.01,1.18], 1.12[1.01,1.24]$, and $1.19[1.04,1.38]$ respectively, but not with hospital mortality.

\section{Discussion}

In this retrospective observational study, we found the time spent in MAP of $\leq 55 \mathrm{mmHg}$ and $\leq 60 \mathrm{mmHg}$ was associated with higher ICU mortality, while MAP of $\leq 65 \mathrm{mmHg}$ or more was not associated with ICU mortality, which implied MAP of $\geq 60 \mathrm{mmHg}$ may be appropriate. The time spent in MAP of $\leq 90 \mathrm{mmHg}$, $\leq 95 \mathrm{mmHg}$ and $\leq 100 \mathrm{mmHg}$ was associated with a higher odds ratio for a discharged home outcome, which implied MAP of $\geq 90 \mathrm{mmHg}$ or more might be associated with lower probability of discharged home 
outcome, which implied MAP of $\leq 90 \mathrm{mmHg}$ seemed to be appropriate. We concluded that the MAP between 60-90mmHg range may be appropriate for post-cardiac arrest patients with vasopressor support. Patients after cardiac arrest often developed to post-cardiac arrest syndrome (PCAS), which includes systemic inflammatory response and reperfusion-related damage(15). Hemodynamic instability is common for post cardiac arrest patients, which can lead to vascular paralysis in the stage of ischemia-reperfusion injury(16). In addition, the cerebrovascular autoregulation is often right-shifted among some PCA patients, mainly for those who have been treated with antihypertensive drugs for a long time(9), which suggest that hemodynamics should be optimized in the early phase(17).

American Heart Association (AHA) guideline statements recommend a MAP threshold of $\geq 65 \mathrm{mmHg}(18)$ and current guidelines recognized that the evidence for targeted blood pressure is weak(10). Previous studies found the hypotension, particularly below the lower limit of autoregulation, among post-CA patients is associated with higher hospital mortality $(13,19-22)$. In order to optimize post-resuscitation care, the management of blood pressure is very essential. Russo et al. retrospectively found that during the first 96h, the higher ABT (ABT=area below blood pressure threshold, mmHg*hours) was associated with increased rates of severe neurological dysfunction when MAP thresholds $<75 \mathrm{mmHg}$ is used(19). Kilgannon et al. prospectively found the time-weighted average mean arterial pressure(TMA-MAP) was associated with the good neurologic outcome when the MAP threshold was greater than $70 \mathrm{mmHg}$ in the first $6 \mathrm{~h}$ after $\operatorname{ROSC}(21)$. Laurikkala et al. prospectively found an association between unfavorable neurological outcome and time spent below a MAP of $70 \mathrm{mmHg}$ in the first $48 \mathrm{~h}$ after ROSC, but did not find an association between high vasopressor load and poor outcome(23). In 2019, the Neuro-protect postCA trial, compared the current standard of care (MAP 65mmHg) with a goal-directed hemodynamic 
optimization strategy (MAP 85-100mmHg, SVO2 65-75\%) found targeting a higher MAP improved brain oxygenation but did not improve the neurological outcome(24).

The current analysis found the proportion of using vasopressors is higher among non-survivors, which is consistent with the findings of previous observational studies(20, 22, 25). Although previous studies have shown an association between higher MAP goals achieved with vasopressors and improved outcomes $(21,24)$, a high dosage of vasopressors could cause complications, such as arrhythmia and decreased peripheral perfusion(26). We also found the proportion of using hypothermia is higher among non-survivors, which might not have clinical significance. Targeted temperature management (TTM) is a cornerstone of resuscitation care after cardiac arrest(27). However, the optimal goal temperature, duration of TTM, and optimal method or device for targeted temperature management (TTM) after cardiac arrest has not yet been defined(16).

We acknowledge that our study has some important limitations to consider. First, the value of our study is limited by its observational design, and analysis based on data collected retrospectively, thus the causal relationship between MAP and outcomes cannot be verified. Second, despite adjusted analyses were performed, many potential confounders might not have been recognized, which would influence our statistical results. We did not have the data to know at the type and etiology of cardiac arrest, rhythm of cardiac arrest, prehospital use of epinephrine and its dosage, time from collapse to CPR and time from CPR to ROSC. High-quality CPR is of crucial importance in post-cardiac arrest care(28) and could be an undeniable confounding factor. Third, we included both in-hospital and out-of-hospital cardiac arrest patients according to this database. Patients hospitalized in the emergency department are usually classified as out-of-hospital cardiac arrest patients with higher mortality. Fourth, due to lack of relevant 
data, we used discharged home outcome as an index of neurological function, as studies have used the same method before. Additional cerebral perfusion measurements would be informative, because discharged home outcome could not provide an accurate representation of the neurologic function. In addition, MBP measurement may be too crude to target in PCA patients, and it may be more clinically significant to examine the relationship between increasing or decreasing MAP and other tissue perfusion variables including cardiac index, regional blood flow, and microcirculatory flow(29).

\title{
5. Conclusion
}

In the present study, higher MAP supported with vasopressors is associated with lower ICU mortality. Time spent in MAP of $\leq 60 \mathrm{mmHg}$ or less was associated with higher ICU mortality and MAP of $\geq 90$ $\mathrm{mmHg}$ or more was associated with a lower probability for discharged home. These results imply that the MAP between 60 and 90 may be appropriate for post-cardiac arrest patients with vasopressor support. Due to the study design a cause-and-effect relationship cannot be firmly established, but the results are encouraging.

\author{
Abbreviations \\ MAP: Mean arterial pressure; CA: Cardiac arrest; ICU: Intensive care unit; CPR: Cardiopulmonary \\ resuscitation; ROSC: Return of spontaneous circulation; APACHE: Acute Physiology and Chronic Health \\ Evaluation; TWA-MAP: Time-weighted average mean arterial pressure; ORs: Odds ratios; PCI: \\ Percutaneous coronary intervention; TTM: Targeted temperature management; AHA: American Heart \\ Association; OHCA: Out-of-hospital cardiac arrest; ABT: Area below blood pressure threshold;

\section{Ethics approval and consent to participate}

IRB approval was obtained prior to initiation of study. 


\section{Consent for publication}

The authors consent for publication of this manuscript.

\section{Availability of data and materials}

The data were available on the eICU website at https://eicu-crd.mit.edu/.

\section{Competing interests}

The authors declare that they have no competing interests.

\section{Funding}

This study was supported by grants from 'Beijing Municipal Science and Technology Commission-

Capital clinical application research' (Z181100001718068) and 'Medical fund research project'(B17233-

032).

\section{Authors' contributions}

DWZ and ZML: data collection, statistical analysis, and manuscript drafting. SLZ and LW: study conduct and manuscript revision. GZS: principal investigator, study design and manuscript drafting. All authors read and approved the final manuscript.

\section{Acknowledgments}

We would like to express our heartfelt thanks to our family members for their spiritual support in the process of this study.

\section{References}

1. Andersen LW, Holmberg MJ, Berg KM, Donnino MW, Granfeldt A. In-Hospital Cardiac Arrest: A Review. Jama. $2019 ; 321(12): 1200-10$.

2. Wang J, Ma Q, Zhang H, Liu S, Zheng Y. Predictors of survival and neurologic outcome for adults with extracorporeal cardiopulmonary resuscitation: A systemic review and meta-analysis. Medicine. 2018;97 (48):e13257.

3. Go AS, Mozaffarian D, Roger VL, Benjamin EJ, Berry JD, Blaha MJ, et al. Heart disease and stroke statistics-2014 update: a report from the American Heart Association. Circulation. 2014;129(3):e28-e292. 
4. Nielsen N, Wetterslev J, Cronberg T, Erlinge D, Gasche Y, Hassager C, et al. Targeted temperature management at $33^{\circ} \mathrm{C}$ versus $36^{\circ} \mathrm{C}$ after cardiac arrest. The New England journal of medicine. 2013;369 (23):2197-206.

5. Lemiale V, Dumas F, Mongardon N, Giovanetti 0, Charpentier J, Chiche JD, et al. Intensive care unit mortality after cardiac arrest: the relative contribution of shock and brain injury in a large cohort. Intensive Care Med. $2013 ; 39(11): 1972-80$.

6. Laver S, Farrow C, Turner D, Nolan J. Mode of death after admission to an intensive care unit following cardiac arrest. Intensive Care Med. 2004;30(11):2126-8.

7. Roberts BW, Kilgannon JH, Chansky ME, Mittal N, Wooden J, Parrillo JE, et al. Multiple organ dysfunction after return of spontaneous circulation in postcardiac arrest syndrome. Crit Care Med. 2013;41 (6):1492-501.

8. Sundgreen C, Larsen FS, Herzog TM, Knudsen GM, Boesgaard S, Aldershvile J. Autoregulation of cerebral blood flow in patients resuscitated from cardiac arrest. Stroke. 2001;32(1):128-32.

9. KUDOH HNaI. Cerebral autoregulation is impaired in patients resuscitated after cardiac arrest. Acta Anaesthesiol Scand 1996; 40: 1149-1153. 1996.

10. Callaway CW, Donnino MW, Fink EL, Geocadin RG, Golan E, Kern KB, et al. Part 8: Post-Cardiac Arrest Care: 2015 American Heart Association Guidelines Update for Cardiopulmonary Resuscitation and Emergency Cardiovascular Care. Circulation. 2015;132(18 Supp1 2):S465-82.

11. Pollard TJ, Johnson AEW, Raffa JD, Celi LA, Mark RG, Badawi 0. The eICU Collaborative Research Database, a freely available multi-center database for critical care research. Scientific data. 2018;5:180178.

12. Russo JJ, James TE, Hibbert B, Ramirez FD, Simard T, Osborne C, et al. Hyperglycaemia in comatose survivors of out-of-hospital cardiac arrest. Eur Heart J Acute Cardiovasc Care. 2018;7(5):442-9.

13. Chiu YK, Lui CT, Tsui KL. Impact of hypotension after return of spontaneous circulation on survival in patients of out-of-hospital cardiac arrest. Am J Emerg Med. 2018;36(1):79-83.

14. Vincent JL, Nielsen ND, Shapiro NI, Gerbasi ME, Grossman A, Doroff R, et al. Mean arterial pressure and mortality in patients with distributive shock: a retrospective analysis of the MIMIC-III database. Annals of intensive care. 2018;8(1):107.

15. Walker AC, Johnson NJ. Critical Care of the Post-Cardiac Arrest Patient. Cardiology clinics. 2018;36 (3) :41928.

16. Walker AC, Johnson NJ. Targeted Temperature Management and Postcardiac arrest Care. Emergency Medicine Clinics of North America. 2019;37(3):381-93.

17. Zweifel C, Castellani G, Czosnyka M, Carrera E, Brady KM, Kirkpatrick PJ, et al. Continuous assessment of cerebral autoregulation with near-infrared spectroscopy in adults after subarachnoid hemorrhage. Stroke. $2010 ; 41(9): 1963-8$.

18. Peberdy MA, Callaway CW, Neumar RW, Geocadin RG, Zimmerman JL, Donnino M, et al. Part 9: post-cardiac arrest care: 2010 American Heart Association Guidelines for Cardiopulmonary Resuscitation and Emergency Cardiovascular Care. Circulation. 2010;122(18 Supp1 3):S768-86.

19. Russo JJ, Di Santo P, Simard T, James TE, Hibbert B, Couture E, et al. Optimal mean arterial pressure in comatose survivors of out-of-hospital cardiac arrest: An analysis of area below blood pressure thresholds. Resuscitation. 2018;128:175-80.

20. Russo JJ, James TE, Hibbert B, Yousef A, Osborne C, Wells GA, et al. Impact of mean arterial pressure on clinical outcomes in comatose survivors of out-of-hospital cardiac arrest: Insights from the University of 0ttawa Heart Institute Regional Cardiac Arrest Registry (CAPITAL-CARe). Resuscitation. 2017;113:27-32.

21. Kilgannon JH, Roberts BW, Jones AE, Mittal N, Cohen E, Mitchell J, et al. Arterial blood pressure and 
neurologic outcome after resuscitation from cardiac arrest*. Crit Care Med. 2014;42(9):2083-91.

22. Beylin ME, Perman SM, Abella BS, Leary M, Shofer FS, Grossestreuer AV, et al. Higher mean arterial pressure with or without vasoactive agents is associated with increased survival and better neurological outcomes in comatose survivors of cardiac arrest. Intensive Care Med. 2013;39(11):1981-8.

23. Laurikkala J, Wilkman E, Pettilä V, Kurola J, Reinikainen M, Hoppu S, et al. Mean arterial pressure and vasopressor load after out-of-hospital cardiac arrest: Associations with one-year neurologic outcome. Resuscitation. 2016;105:116-22.

24. Ameloot K, De Deyne C, Eertmans W, Ferdinande B, Dupont M, Palmers PJ, et al. Early goal-directed haemodynamic optimization of cerebral oxygenation in comatose survivors after cardiac arrest: the Neuroprotect post-cardiac arrest trial. Eur Heart J. 2019;40(22) :1804-14.

25. Bro-Jeppesen J, Kjaergaard J, Soholm H, Wanscher M, Lippert FK, Moller JE, et al. Hemodynamics and vasopressor support in therapeutic hypothermia after cardiac arrest: prognostic implications. Resuscitation. 2014;85(5):66470.

26. Giraud R, Siegenthaler N, Bendjelid K. Cardiac index during therapeutic hypothermia: which target value is optimal? Crit Care. 2013;17(2):214.

27. Silverman MG, Scirica BM. Cardiac arrest and therapeutic hypothermia. Trends in cardiovascular medicine. $2016 ; 26(4): 337-44$.

28. Perkins GD, Travers AH, Berg RA, Castren M, Considine J, Escalante R, et al. Part 3: Adult basic life support and automated external defibrillation: 2015 International Consensus on Cardiopulmonary Resuscitation and Emergency Cardiovascular Care Science with Treatment Recommendations. Resuscitation. 2015;95:e43-69.

29. Augusto JF, Teboul JL, Radermacher P, Asfar P. Interpretation of blood pressure signal: physiological bases, clinical relevance, and objectives during shock states. Intensive Care Med. 2011;37(3):411-9.

\section{Figure legend}

Fig.1. Method to calculate the percentage of time spent in mean arterial pressure (MAP) threshold. This figure displayed MAP every 5 minutes for one patient during the first 24 hours (1440 min) after admitting to ICU. There were two points below the MAP threshold of $60 \mathrm{mmHg}$, meaning time spent in MAP $\leq 60 \mathrm{mmHg}$ was 10 $\min (2 * 5=10)$. Then, the percentage of time spent in MAP $\leq 60 \mathrm{mmHg}$ was $10 / 1440 * 100 \%=0.7 \%$. Similarly, percentage of time spent in $\mathrm{MAP} \leq 55 \mathrm{mmHg}$ was $0 \%$, MAP $\leq 65 \mathrm{mmHg}$ was $1.7 \%, \mathrm{MAP} \leq 70 \mathrm{mmHg}$ was $19.1 \%$, MAP $\leq 75 \mathrm{mmHg}$ was $53.5 \%$, MAP $\leq 80 \mathrm{mmHg}$ was $82.9 \%$, MAP $\leq 85 \mathrm{mmHg}$ was $92.2 \%$, MAP $\leq 90 \mathrm{mmHg}$ was 97\%, MAP $\leq 95 \mathrm{mmHg}$ was $98.6 \%$, MAP $\leq 100 \mathrm{mmHg}$ was $99 \%$, respectively.

Fig. 2. Flow chart of patient selection. 
Fig. 3. Unadjusted ICU mortality of four time-categories $(0-25 \%, 25-50 \%, 50-75 \%$, and $75-100 \%)$ spent in ten MAP thresholds $(55 \mathrm{mmHg}, 60 \mathrm{mmHg}, 65 \mathrm{mmHg}, 70 \mathrm{mmHg}, 75 \mathrm{mmHg}, 80 \mathrm{mmHg}, 85 \mathrm{mmHg}, 90 \mathrm{mmHg}, 95 \mathrm{mmHg}$, and100mmHg). Of note, when the percentage of time spent in MAP below $60 \mathrm{mmHg}$ or $55 \mathrm{mmHg}$ was more than three quarters, the ICU mortality were as high as $80 \%$ and $82 \%$, respectively. ICU intensive care unit, MAP mean arterial pressure.

Supplemental Fig. 1. Adjusted odds ratio for hospital mortality and discharged home outcomes for different MAP thresholds. A is adjusted odds ratio for hospital mortality, and B for discharged home according to different MAP categories. The adjusted odds ratio for each MAP category and 95\% confidence intervals (error bars) were calculated after multivariable adjustment for age, gender, comorbidities of hypertension, diabetes mellitus, chronic heart failure, renal insufficiency, chronic obstructive pulmonary disease, acute physiology score, use of hypothermia, percutaneous coronary intervention. An odds ratio is calculated per 5\% increase in time in each given category. 


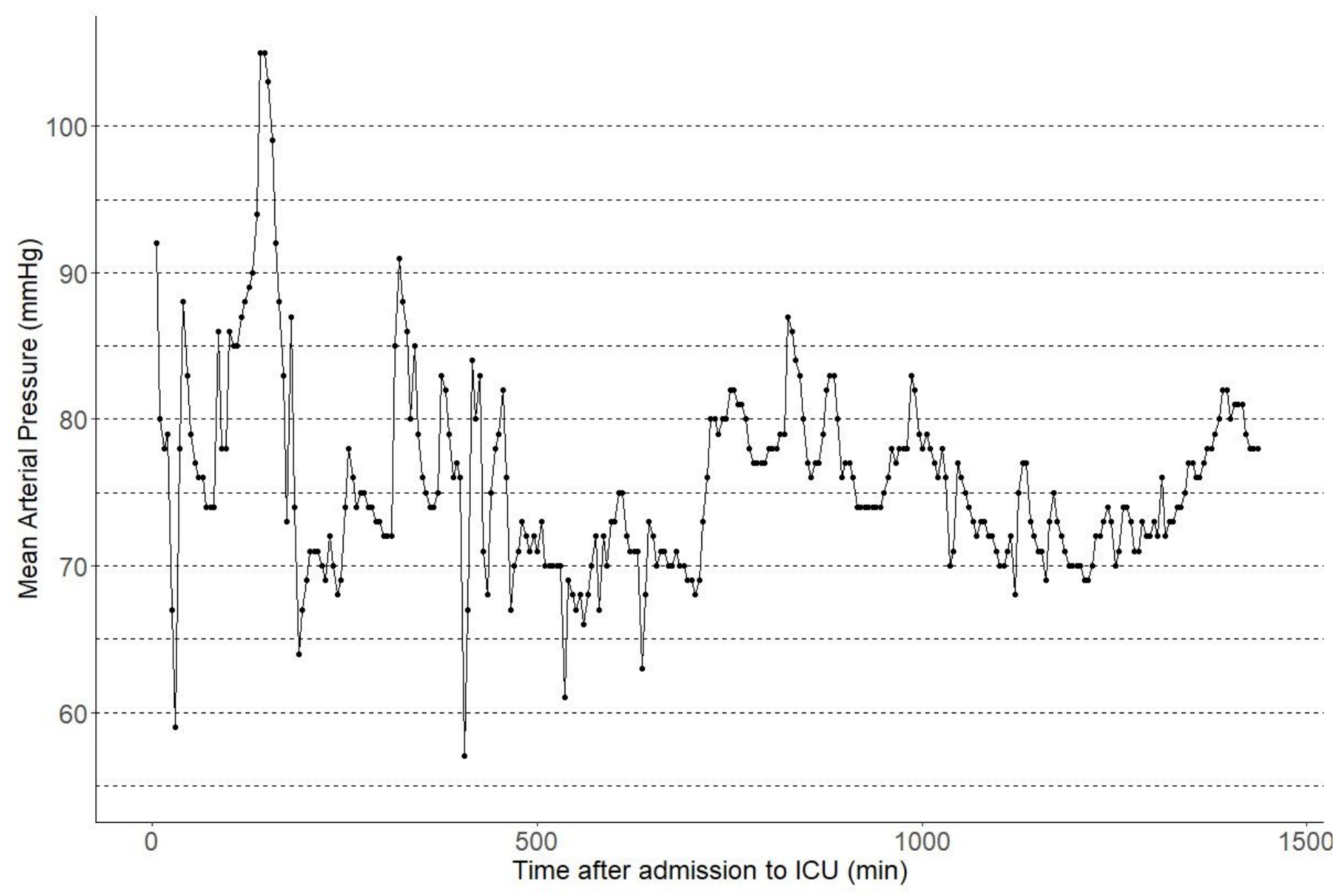

Figure 1

Method to calculate the percentage of time spent in mean arterial pressure (MAP) threshold. This figure displayed MAP every 5 minutes for one patient during the first 24 hours (1440 $\mathrm{min}$ ) after admitting to ICU. There were two points below the MAP threshold of $60 \mathrm{mmHg}$, meaning time spent in MAP $\leq 60 \mathrm{mmHg}$ was $10 \mathrm{~min}(2 \star 5=10)$. Then, the percentage of time spent in MAP $\leq 60 \mathrm{mmHg}$ was $10 / 1440 \star 100 \%=0.7 \%$. Similarly, percentage of time spent in MAP $\leq 55 \mathrm{mmHg}$ was $0 \%$, MAP $\leq 65 \mathrm{mmHg}$ was $1.7 \%$, MAP $\leq 70$ mmHg was $19.1 \%$, MAP $\leq 75 \mathrm{mmHg}$ was $53.5 \%$, MAP $\leq 80 \mathrm{mmHg}$ was $82.9 \%$, MAP $\leq 85 \mathrm{mmHg}$ was 92.2\%, MAP $\leq 90 \mathrm{mmHg}$ was $97 \%$, MAP $\leq 95 \mathrm{mmHg}$ was $98.6 \%$, MAP $\leq 100 \mathrm{mmHg}$ was $99 \%$, respectively. 


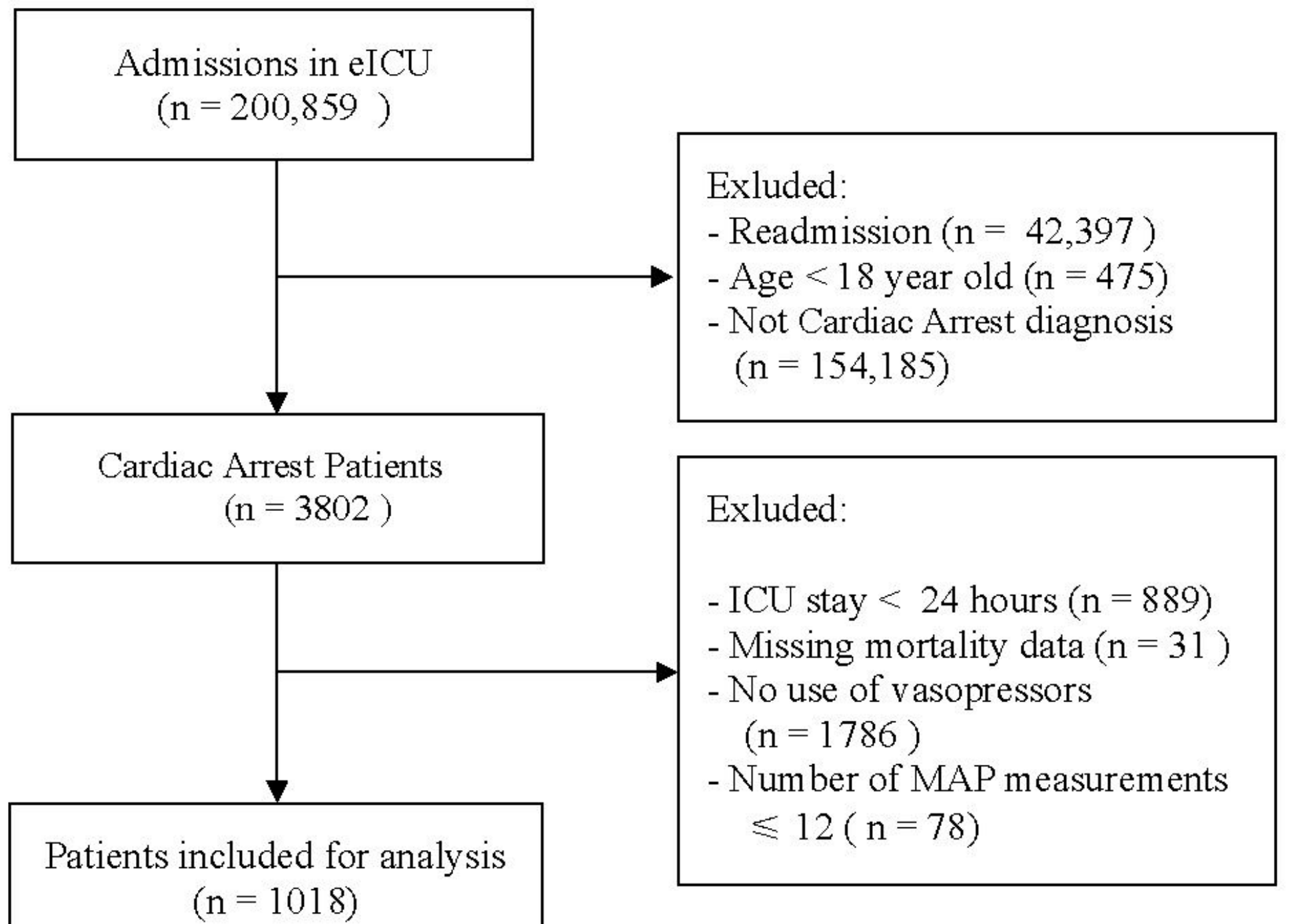

Figure 2

Flow chart of patient selection. 


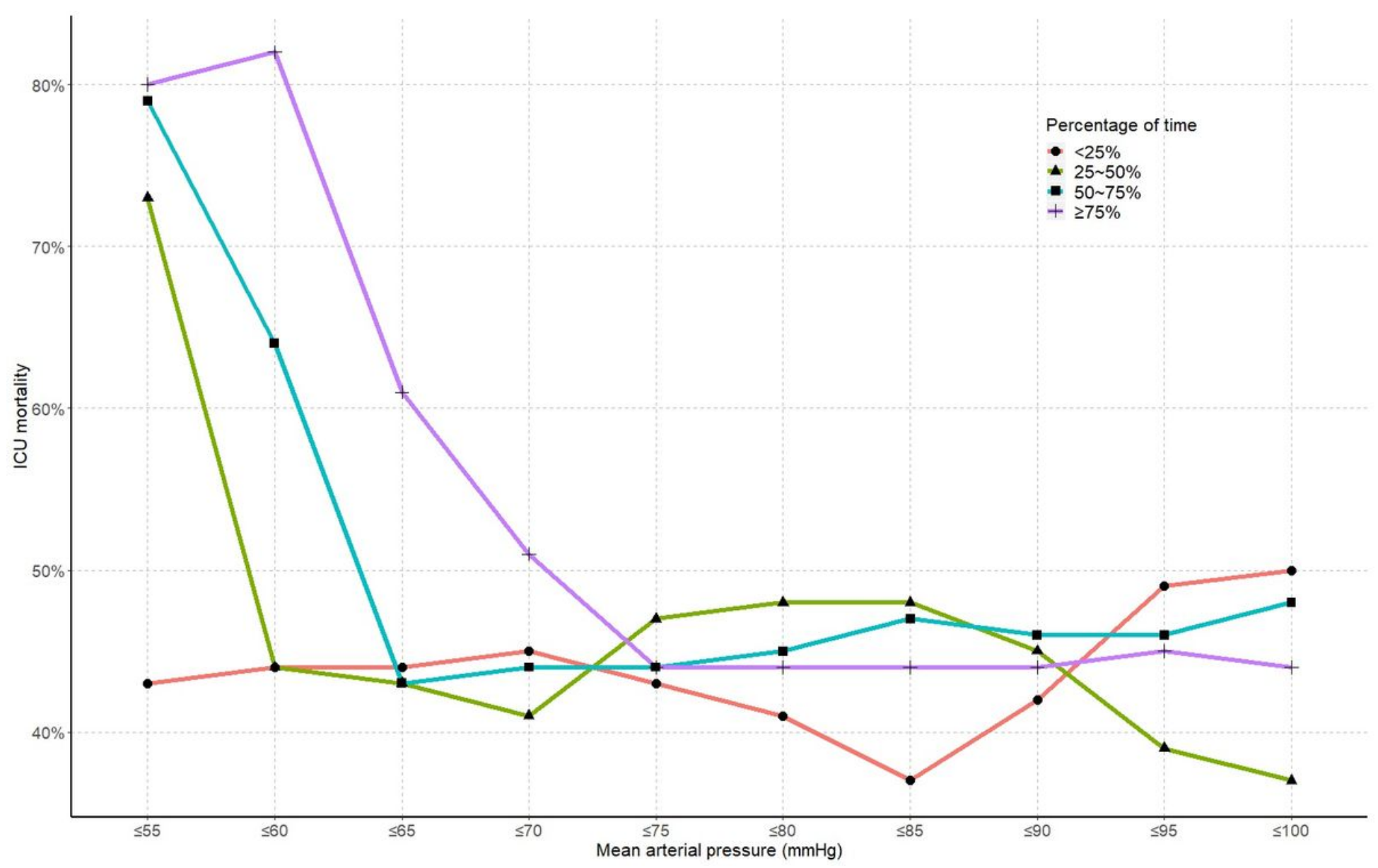

Figure 3

Unadjusted ICU mortality of fourtime-categories (0-25\%, 25-50\%, 50-75\%, and 75-100\%) spent in ten MAP thresholds $(55 \mathrm{mmHg}, 60 \mathrm{mmHg}, 65 \mathrm{mmHg}, 70 \mathrm{mmHg}, 75 \mathrm{mmHg}, 80 \mathrm{mmHg}, 85 \mathrm{mmHg}, 90 \mathrm{mmHg}, 95 \mathrm{mmHg}$, and $100 \mathrm{mmHg}$ ). Of note, when the percentage of time spent in MAP below $60 \mathrm{mmHg}$ or $55 \mathrm{mmHg}$ was more than three quarters, the ICU mortality were as high as $80 \%$ and $82 \%$, respectively.ICU intensive care unit, MAP mean arterial pressure.

\section{Supplementary Files}

This is a list of supplementary files associated with this preprint. Click to download.

- SupplementalFigure1.tif

- table1.pdf

- table3.pdf

- table2.pdf 